\title{
Serum calcium in pulmonary tuberculosis
}

\author{
Subhash C. Sharma \\ M.D., F.R.I.P.H.H. \\ Department of Pathology, Military Hospital, Jabalpur, India 482001
}

\begin{abstract}
Summary
Serum calcium was studied serially in 94 patients with active pulmonary tuberculosis. An equal number of age- and sex-matched patients with chronic obstructive pulmonary disease were controls. Seventy patients in the study group were normocalcaemic and 10 were hypercalcaemic. These 10 were on a higher supplement of vitamin $D$ than the 70 normocalcaemic patients. There was a positive correlation between the daily vitamin intake and the degree and duration of hypercalcaemia. None of the controls showed hypercalcaemia.
\end{abstract}

\section{Introduction}

It is known that alterations in serum calcium concentration occur in association with various granulomatous diseases. Hypercalcaemia occurs frequently in many of these conditions. Sarcoidosis is the most common granulomatous disease causing hypercalcaemia (Reiner et al., 1976). Tuberculosis (TB), disseminated coccidioidomycosis, histoplasmosis and chronic beryllium poisoning have been infrequently reported as associated with altered serum calcium concentrations (Shai et al., 1972; Sherman, Lamon and Winsor, 1972; Walker et al., 1977). The pattern of serum calcium in pulmonary TB is not clear. The paucity of reports prompted this study.

The author has attempted to assess the incidence and the pattern of such changes, if any, in patients admitted to the Military Hospital, Jabalpur, with active pulmonary TB over the last 3 years.

\section{Materials and methods}

The medical records of all patients with active pulmonary TB were reviewed. The diagnosis was established from sputum smears or cultures positive for Mycobacterium tuberculosis in all cases. Other recorded clinical data were the determination of serum calcium, phosphorus, alkaline phosphatase, blood urea nitrogen, bilirubin, and total serum proteins, anti-TB drugs used, dietary regimens and vitamin D supplements. All other possible causes of hypo- or hypercalcaemia, such as metabolic and neoplastic disease, primary hypo- or hyper $\frac{80}{7}$ parathyroidism, milk-alkali syndrome, adrenal 3 . dysfunction and thyroid malfunction had been $y$ excluded by careful investigation. Renal function 2 tests to detect tuberculous infection were madew wherever indicated.

The control group was composed of an equal number of age-matched patients with chronic 5 obstructive pulmonary disease admitted for treat- $\vec{z}$ ment. Similar clinical data as for the study groupo were noted. All subjects in both groups were male. Both groups stayed in hospital for a similar length $\bar{\partial}$ of time. After an overnight fast, venous blood wass drawn for the determination of calcium, phosphor $\vec{G}, \vec{\bullet}$ alkaline phosphatase, blood urea nitrogen, bilirub and total serum proteins. Serum calcium was est. mated with the Clark-Collip (1925) oxalate pre-O cipitation method with permanganate titration of the oxalate. To eliminate the false evaluation of serum calcium due to binding of calcium to serum $\frac{\alpha}{\varnothing}$ proteins in patients with hyperproteinaemia, serum $\cong$ calcium was corrected according to the method of $\overrightarrow{\overrightarrow{0}}$ Alserver and Gotlin (1975). This correction was not 3 used for patients with hypoproteinaemia. Standard techniques were used for the other biochemical estimations.

Serum calcium concentration was measured on $\frac{3}{3}$. admission and at 1- to 2-weekly intervals for most $\frac{3}{3}$ of the treatment period. Hypo- or hypercalcaemia was defined as a serum calcium concentration $<$ or $ᄋ$ $>1.75$ and $2.63 \mathrm{mmol} / \mathrm{l}$ respectively on 2 or more occasions.

\section{Results}

Altogether, 94 cases of pulmonary TB were N reviewed during the study. Eighty-nine had positive sputum smears with negative cultures, and one had a ${ }_{N}$ positive smear and culture. Treatment of pulmonary $\omega$ TB included a combination of 2 or more of the following: ethambutol, isoniazid, para-aminosali- 6 cylic acid, and streptomycin. All patients received $\Phi$ pyridoxine therapy. Patients were isolated for $a^{?}$ period of from 2 to 4 weeks if necessary.

Of the 94 patients, 74 were normocalcaemic $\frac{\partial}{\mathbb{D}}$ 
(mean \pm s.d., $2 \cdot 30 \mathrm{mmol} / 1 \pm 0 \cdot 22$ ), 18 were hypercalcaemic and 2 were hypocalcaemic ( 1.80 and 1.75 respectively). The cause of hypercalcaemia was neoplastic disease in 4 and unexplained in 14 patients whose ages ranged from 26 to 76 years (mean 51.1) (serum calcium concentrations $>2.63$ $\mathrm{mmol} / \mathrm{l})$, an incidence of $15.5 \%$. Six patients had serum calcium concentrations $>2.75 \mathrm{mmol} / 1$ and one had serum calcium $>3 \mathrm{mmol} / \mathrm{l}$. None of the controls, whose ages ranged from 27 to 83 years (mean, 54.4 years), developed hypercalcaemia.

The mean ( \pm s.d.) serum calcium concentration was similar in both groups $(2 \cdot 36 \pm 0.29 \mathrm{mmol} / \mathrm{l}$ in the study group and $2 \cdot 36 \pm 0 \cdot 13 \mathrm{mmol} / \mathrm{l}$ in the controls; NS).

The mean $( \pm$ s.d.) serum phosphorus concentration was higher in the unexplained hypercalcaemic patients $(1 \cdot 49 \pm 0.17 \mathrm{mmol} / 1 ; n, 14)$ than in the normocalcaemic group with pulmonary TB (1.31 $0.21 \mathrm{mmol} / \mathrm{l} ; n, 57 ; \mathrm{NS})$ and the chronic obstructive pulmonary disease group $(\mathbf{1} \cdot 23 \pm \mathbf{0 . 2 7} \mathrm{mmol} / \mathrm{l}, n$, $90 ; P<0.01)$. Serum alkaline phosphatase was not increased in hypercalcaemic compared with normocalcaemic patients, or compared with the patients with chronic obstructive pulmonary disease. There was an increase in blood urea nitrogen in the hypercalcaemic patients $(3 \cdot 10 \pm 1.20 \mathrm{mmol} / \mathrm{l})$ compared to the normocalcaemic group with pulmonary TB $(2.31 \pm 1.31 \mathrm{mmol} / 1 ; P<0.001)$. In 2 patients, the 24-hr urinary calcium excretion on a diet containing $400 \mathrm{mg}$ of calcium was 8.2 and $8.93 \mathrm{mmol} / \mathrm{l}$. There was no evidence of parathyroid dysfunction. Adrenal malfunction was excluded by the lack of clinical manifestations of the disease, and normal serum electrolytes in all patients. Most patients showed no renal involvement as evidenced by normal renal function tests in the normocalcaemic group.

All hypercalcaemic patients except 4 received multivitamin supplements, providing additional vitamin $D$ to the average daily intake of $380 \mathrm{i} . \mathrm{u}$. contained in their food. One patient received 3800 i.u., another received 1400 i.u. and the rest 800 i.u. or less/day of vitamin D supplement administered orally. This increase in the daily intake of vitamin D by the hypercalcaemic group was contrasted with the smaller amount of vitamin $\mathrm{D}$ taken by the normocalcaemic group with TB. In the latter group, 54 patients $(73 \%)$ received a daily supplement not $>400$ i.u. Thirteen of the controls received 400 i.u. of the supplement. The mean \pm s.e. mean of the daily vitamin $D$ supplement in the hypercalcaemic group was $>$ that in the normocalcaemic group $(680 \pm 168$ i.u. and $287 \pm 37$ i.u. respectively, $\boldsymbol{P}<0.02)$. The hypercalcaemic group showed a positive correlation between the daily vitamin $\mathrm{D}$ supplement and the degree and duration of hypercalcaemia. There was no connection between the anti-TB chemotherapy and the induction of hypercalcaemia. Reduced physical activity during isolation did not seem to be related to the onset, degree or duration of hypercalcaemia.

All TB patients were normocalcaemic at the time of admission or at first detection of the bacillus: the onset of hypercalcaemia occurred 4-16 weeks later (mean \pm s.d. $10 \pm 3 \cdot 2$ weeks). Hypercalcaemia usually occurred when the sputum was positive for acid fast bacilli and while the patient was on anti-TB drugs. No patient had symptoms or complications related to hypercalcaemia, the duration of which ranged from one to six months; it remitted spontaneously with adequate hydration or the discontinuation of vitamin D supplement. The elevated serum calcium returned to normal in 12 of the hypercalcaemic patients when their sputum became negative for M. tuberculosis, despite continued supplementation with the same dose of vitamin D. Serum calcium concentrations remained normal in all patients during a follow-up period of 6-9 months.

\section{Discussion}

The prolonged stay in hospital followed by domiciliary treatment undergone by most TB patients provided a good opportunity for the study of the pattern of serum calcium in this disease. Most subjects in this study were normocalcaemic, and hypercalcaemia was observed in only $15.5 \%$. During this time, none of the controls developed hypercalcaemia.

Hypercalcaemia, although observed in only a small percentage of patients, remains unexplained. It was, however, characterized by appearance during the active phase of the disease. Spontaneous remission after the bacillus was no longer present in the sputum, the lack of symptoms in most patients, hyperphosphataemia and slight impairment of renal function, hypercalciuria and normal serum alkaline phosphatase were other features. Most of the patients in the study were culture negative.

The mechanism of hypercalcaemia in these patients is unclear. Involvement of bone or adrenals by TB is a possible cause (Braman, Goldman and Schwartz, 1973). But there was no clinical evidence of these conditions. Tuberculosis of bone as a cause of hypercalcaemia in these patients was unlikely as hypercalcaemia was not present on admission and only occurred a few weeks after starting anti-TB therapy and vitamin D supplements. Acute bone atrophy due to reduced physical activity (Wolf et al., 1976) was not a danger as the time of isolation was short, patients were not confined to bed, and no connection between the time of isolation and onset of hypercalcaemia was noted. 
Vitamin D supplements were given to $71 \%$ of the hypercalcaemic and $73 \%$ of the normocalcaemic patients. The mean vitamin D supplement, however, was higher in the hypercalcaemic than in the normocalcaemic group, so increased sensitivity to vitamin $\mathbf{D}$ may be a possible cause.

The major organ responsible for metabolism of prostaglandin $\mathrm{E}$ compounds is the lung-more than two-thirds of prostaglandin $E$ is extracted in a single transit (Golub et al., 1975). Since prostaglandin $\mathrm{E}$ compounds are potent stimulators of bone resorption degraded primarily in the lung (Klein and Raisz, 1970), extensive tuberculous involvement of the lung could theoretically reduce the rate of degradation, leading to hypercalcaemia. But the findings in this study do not support this as most patients did not show hypercalcaemia.

The pathogenesis of hypercalcaemia in pulmonary tuberculosis may involve more than one simple factor. Whatever the mechanism, there is the possibility that a modest increase in vitamin $D$ in the daily diet may cause hypercalcaemia in patients with active pulmonary TB. Caution should therefore be exercised to avoid hypervitaminosis when such patients are given vitamin supplements.

\section{References}

AlSERVER, R.N. \& Gotlin, R.W. (1975) The parathyroids.
In: Handbook of Endocrine Function Tests in Adults and $\underset{\mathbb{Q}}{\Phi}$ Children, p. 77. Chicago Year Book Medical Publications C Inc.

Braman, S.S., Goldman, A.L. \& Schwartz, M.I. (1973) Steroid-responsive hypercalcemia in disseminated bone tuberculosis. Archives of Internal Medicine, 132, 269.

Clark, E.P. \& Collip, J.B. (1925) A study of the Tisdall $\frac{\bar{V}}{\bar{D}}$ method for the determination of blood serum calcium $\frac{5}{7}$ with a suggested modification. Journal of Biological $\mathbb{\varnothing}$ Chemistry, 63, 461.

Golub, M., Zia, P., Matsuno, M. \& Horton, R. (1975) ڤ્ Metabolism of prostaglandin A1 and E, in man. Journal $\overrightarrow{0}$ of Clinical Investigation, 56, 1404.

KLEIN, D.C. \& RAISz, L.G. (1970) Prostaglandin: stimu- $\overrightarrow{\vec{\omega}}$ lation of bone resorption in tissue culture. Endocrinology, 86, 1436.

Reiner, M., Sigurdusson, G., Nunziata, V., Malik, M.A., Poole, G.M. \& Joplin, G.F. (1976) Abnormal calcium metabolism in normocalcaemic sarcoidosis. British G Medical Journal, 2, 1473.

Shai, F., BaKer, R.K., AdDrizzo, J.R. \& Wallach, S. (1972) Hypercalcemia in mycobacterial infection. Journal of Clinical Endocrinology and Metabolism, 34, 251.

Sherman, O.P., Lamon, J. \& Winsor, D. (1972) Hypercalcemia and tuberculosis (Letter). Journal of the American Medical Association, 222, 582.

Walker, J.V., Baren, D., Yakub, Y.N. \& Freeman, R.B. Z (1977) Histoplasmosis with hypercalcemia, renal failure and papillary necrosis. Confusion with sarcoidosis. $\frac{\Phi}{7}$ Journal of the American Medical Association, 237, 1350.

Wolf, A.W., Chuinard, R.G., Riggins, R.S., Walteg, R.M. \& DEPNER, T. (1976) Immobilisation hypercalcemia. $\vec{\theta}$ Clinical Orthopedics, 118, 124. 